\title{
Real-time monitoring of trace-level VOCs by an ultrasensitive lamp-based VUV photoionization mass spectrometer
}

\author{
W. Q. Sun, J. N. Shu, P. Zhang, Z. Li, N. N. Li, M. Liang, and B. Yang \\ State Key Joint Laboratory of Environment Simulation and Pollution Control, Research Center for Eco-Environmental \\ Sciences, Chinese Academy of Sciences, Beijing, China \\ Correspondence to: J. N. Shu (jshu@rcees.ac.cn)
}

Received: 21 March 2015 - Published in Atmos. Meas. Tech. Discuss.: 15 June

Revised: 7 October 2015 - Accepted: 21 October 2015 - Published: 4 November 2015

\begin{abstract}
In this study, we report on the development of a lamp-based vacuum ultraviolet photoionization mass spectrometer (VUV-PIMS) in our laboratory; it is composed of a radio-frequency-powered VUV lamp, a VUV photoionizer, an ion-migration lens assembly, and a reflection timeof-flight mass spectrometer. By utilizing the novel photoionizer consisting of a photoionization cavity and a VUV light baffle, the baselines of the mass spectra decreased from $263.6 \pm 15.7$ counts to $4.1 \pm 1.8$ counts. A detection limit $(2 \sigma)$ of 3 pptv was achieved for benzene after an acquisition time of $10 \mathrm{~s}$. To examine its potential for real-time monitoring applications of samples, the developed VUV-PIMS was employed for the continuous measurement of urban air for 6 days in Beijing, China. Strong signals of trace-level volatile organic compounds, such as benzene and its alkylated derivatives, were observed in the mass spectra. These initial experimental results reveal that the instrument can be used for the online monitoring of trace-level species in the atmosphere.
\end{abstract}

\section{Introduction}

Volatile organic compounds (VOCs) are an important group of air pollutants: they are active in the formation of photochemical smog and ground-level ozone production; several VOCs present in urban air, such as benzene and its alkylated derivatives, are considered carcinogenic (Gee and Sollars, 1998; Lee et al., 2005). The average volume fractions of VOCs in the atmosphere are generally less than $1 \times 10^{-9}$ (ppbv) (Elsom, 1996; Schubert et al., 1999). Because of this low VOC concentration, sample enrichment is often necessary prior to VOC analysis. During sampling or analysis, some active species might be oxidized by ozone (Jaouen et al., 1995) or other oxidizing agents, thereby decreasing the representativity of sampling. Meanwhile, conventional detection approaches such as gas chromatography-mass spectrometry and high-performance liquid chromatographymass spectrometry involve a time-consuming chromatographic separation step (Muhlberger et al., 2002). For these reasons, it is imperative to develop real-time online monitoring instruments with high sensitivity for the detection of VOCs.

The use of the highly sensitive proton-transfer-reaction mass spectrometer (PTR-MS) has been demonstrated for the real-time measurement of trace gases in the atmosphere with limits of detection (LODs) at the pptv level (de Gouw and Warneke, 2007). On the other hand, laser-based photoionization techniques including resonance-enhanced multiphoton ionization MS (Heger et al., 1999; Muhlberger et al., 2004) and single-photon ionization (SPI) MS (Muhlberger et al., 2004; Tonokura et al., 2010) have also been applied for the online detection of VOCs at trace levels $\left(\mathrm{ppbv} p p t v^{-1}\right)$. However, they suffer from limitations such as the use of expensive, bulky, and sophisticated laser systems to achieve nonlinear optical processes (Muhlberger et al., 2002). Meanwhile, the lamp-based vacuum ultraviolet photoionization MS (VUV-PIMS) is another type of instrument that has been attracting significant attention (Muhlberger et al., 2005a). Mühlberger et al. (2007, 2005a, b; 2002) have developed a series of VUV-PIMSs with an electron-beam-pumped rare gas excimer VUV lamp. There is an improvement in the LOD for benzene, toluene, and xylene from ppmv to tens of ppbv. Meanwhile, Hua et al. (2011) have designed a VUV-MS based on a commercial krypton lamp, exhibiting both SPI 
(a)

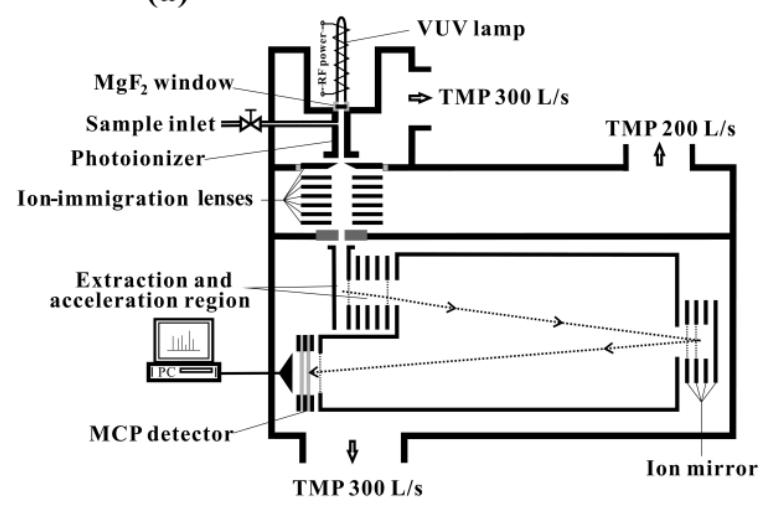

(b) Photoionizer A

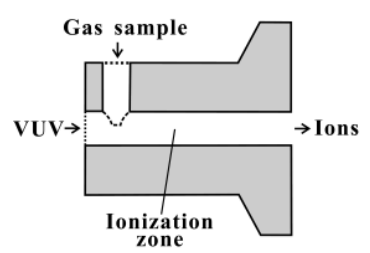

Figure 1. Schematic of the VUV-PIMS (a), photoionizer A (b), and photoionizer B (c). TMP: turbo molecular pump.

and chemical ionization capabilities. The LODs observed for benzene, toluene, and xylene are as low as 3, 4, and 6 ppbv, respectively, in the SPI mode. Meanwhile, Kuribayashi et al. (2005) have developed a VUV-PI-ion-trap MS with a microwave-excited VUV lamp and observed an LOD of $10 \mathrm{pptv}$ for trichlorobenzene after an acquisition time of $18 \mathrm{~s}$.

In this paper, we report the design of a sensitive VUVPIMS, which was employed to measure trace-level VOCs such as benzene. The instrument design, calibration results, and urban air measurements will be discussed in the following sections.

\section{Experimental section}

\subsection{Instrumentation}

Figure 1a shows the laboratory-built VUV-PIMS. Its main components include a radio-frequency-powered (RF) VUV lamp, a VUV photoionizer, an ion-migration lens assembly, and a reflection time-of-flight MS (TOF-MS).

The VUV lamp, which is constructed in our laboratory, is a krypton lamp. Its structure has been reported in detail in the study by Shu et al. (2013). A plano-convex $\mathrm{MgF}_{2}$ lens $(f=50 \mathrm{~mm})$ is used as a window for focusing VUV light into the photoionizer. The output of the lamp is $\sim 5 \times 10^{14}$ photon $\mathrm{s}^{-1}$ at $123.9 \mathrm{~nm}$. Table 1 lists the compar- ison of several sources of VUV light typically used for the detection of VOCs by mass spectrometry.

Figure $1 \mathrm{~b}$ and $\mathrm{c}$ show photoionizers $\mathrm{A}$ and $\mathrm{B}$, respectively, used in the test, which are made of stainless steel. They are interchangeable in the corresponding position of the VUVPIMS. Photoionizer A is a straight channel with a length of $30 \mathrm{~mm}$ and an internal diameter of $6 \mathrm{~mm}$. On the other hand, photoionizer B is designed with an optical baffle for preventing VUV light from entering the ion-migration lens assembly. The diameter of the VUV light baffle is $\sim 2 \mathrm{~mm}$, and the diameter of the exit orifice of photoionizer B is $1.5 \mathrm{~mm}$. First, the sample is introduced into the photoionizer via a stainlesssteel tube (1/8-inch outer diameter; OD) using a needle valve. Moreover, the signal intensity is optimized by controlling the sample flow by adjusting the needle valve. The pressure in the photoionizer is not measured directly but is measured indirectly by the pressure of the foreline measured using a convectron gauge. The estimated pressures inside the photoionizers A and B are $\sim 100-300$ and $\sim 500-1000 \mathrm{~Pa}$, respectively.

Meanwhile, the ion-migration lens assembly contains seven ion-migration lenses. The ions ejected from the photoionizer are focused by the electrostatic fields generated from the ion lenses into a narrow beam and then enter into the reflection MS. To obtain a stronger ion beam, the excitation tube of the VUV lamp, the photoionizer, and the ionmigration lens assembly are concentric.

A V-shaped laboratory-built reflection MS was employed, which consisted of a $230 \mathrm{~mm}$ TOF cavity, an extraction grid, an ion mirror, and a chevron multichannel plate detector. The relatively short TOF cavity is selected to make the instrument compact; hence, a high repetition rate of $35000 \mathrm{~s}^{-1}$ is obtained for better LODs. The path of the ion flight is orthogonal to the axis of the ion-migration lens assembly. The generated ions are extracted with a pulsed electric field of $600 \mathrm{~V}$, $35000 \mathrm{~Hz}$. The voltage of the acceleration field is $1800 \mathrm{~V}$. The chevron microchannel plates used to detect ions are biased at $2100 \mathrm{~V}$. The signal is amplified using a $100 \times$ amplifier (Ortec VT120C) and recorded with a TOF multiscaler (FAST Comtec, P7888). Each mass spectrum is obtained by accumulating ion extractions up to 350000 times, equal to an acquisition time of $10 \mathrm{~s}$ (averaging time).

The three-stage differential pumping system is composed of three chambers: a source chamber, differential chamber, and detection chamber. These chambers are pumped by 300 , 200, and $300 \mathrm{~L} \mathrm{~s}^{-1}$ turbo molecular pumps (TMPs), respectively. The first two TMPs are backed by a rotary pump $\left(8.3 \mathrm{~L} \mathrm{~s}^{-1}\right)$, while the outlet of the third TMP joins the source chamber. Furthermore, during sampling, the working pressures of the reflection MS for photoionizers $\mathrm{A}$ and $\mathrm{B}$ are $\sim 2 \times 10^{-3}$ and $\sim 3 \times 10^{-3} \mathrm{~Pa}$, respectively. 
Table 1. Performance of instruments using different light sources.

\begin{tabular}{|c|c|c|c|c|c|}
\hline Type of VUV & 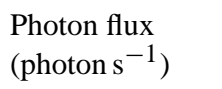 & LOD & Type of MS & Year & Ref. \\
\hline $\begin{array}{l}\text { Radio-frequency-powered } \\
\text { VUV lamp }\end{array}$ & $\begin{array}{l}\sim 5 \times 10^{14} \\
\mathrm{Kr} \\
123.9 \mathrm{~nm}\end{array}$ & 3 pptv for benzene & TOF & 2015 & this study \\
\hline Laser & $\begin{array}{l}\sim 1.6 \times 10^{18} \\
118 \mathrm{~nm}\end{array}$ & $10 \mathrm{ppbv}$ for benzene & TOF & 2010 & (Tonokura et al., 2010) \\
\hline $\begin{array}{l}\text { Electron-beam-pumped } \\
\text { rare gas excimer VUV } \\
\text { lamp (EBEL) }\end{array}$ & $\begin{array}{l}3 \times 10^{17}, \mathrm{kr}_{2} * \\
147 \mathrm{~nm}\end{array}$ & 2 ppmv for benzene & TOF & 2002 & (Muhlberger et al., 2002) \\
\hline EBEL & $\begin{array}{l}1.9 \times 10^{19} \\
\mathrm{Ar}^{*} \\
126 \mathrm{~nm}\end{array}$ & $50 \mathrm{ppbv}$ for benzene & TOF & 2005 & (Muhlberger et al., 2005a) \\
\hline EBEL & $\begin{array}{l}\sim 1.5 \times 10^{13} \\
\operatorname{Ar}^{*}, 126 \mathrm{~nm}\end{array}$ & 50 ppbv for benzene & Quadrupole & 2005 & (Muhlberger et al., 2005b) \\
\hline $\begin{array}{l}\text { Lyman- } \alpha \text { atomic-radiation- } \\
\text { based microwave discharge } \\
\text { lamp }\end{array}$ & $\begin{array}{l}\sim 10^{14} \\
\mathrm{H}_{2} / \mathrm{He} \\
121.6 \mathrm{~nm}\end{array}$ & $10 \mathrm{pptv}$ for trichlorobenzene & Ion trap + TOF & 2005 & (Kuribayashi et al., 2005) \\
\hline Commercial Kr VUV lamp & $\begin{array}{l}10^{11}, \mathrm{Kr} \\
116.5 \mathrm{~nm}\end{array}$ & $35 \mathrm{ppbv}$ for toluene & TOF & 2011 & (Hua et al., 2011) \\
\hline
\end{tabular}

\subsection{Sample preparation}

Samples of 10 and $400 \mathrm{ppbv}$ benzene were used in the experiment, which were prepared by triple dilution. First, pure benzene was diluted 4.1-fold with dichloromethane; then $0.1 \mathrm{~mL}$ of this diluted solution was injected into a $6.35 \mathrm{~L}$ narrowmouthed bottle filled with synthetic air $\left(80 \% \mathrm{~N}_{2}+20 \% \mathrm{O}_{2}\right)$, which was prepared by two mass-flow meters using highpurity nitrogen and oxygen. Thus, the concentration of benzene obtained in the bottle was $1000 \mathrm{ppmv}$. The $10 \mathrm{ppbv}$ sample was prepared by adding $1.2 \mathrm{~mL}$ of 1000 ppmv benzene into a $120 \mathrm{~L}$ smog chamber with a syringe. The chamber was composed of a thin-walled open-head stainless-steel drum and a thin Tedlar polyvinyl fluoride film bag. Adequate mixing was ensured by using a magnetic stirring fan set at the bottom of the chamber. This sample was initially used for optimizing the parameters of the VUV-PIMS such as the RF power and the ion source pressures of photoionizers $\mathrm{A}$ and B. The 400 ppbv sample was prepared by injecting $0.1 \mathrm{~mL}$ of 1000 ppmv benzene into a $0.24 \mathrm{~L}$ cylinder. The cylinder was made of stainless steel with two 1/4-inch tubes serving as the gas inlet and outlet, respectively. Synthetic air at a flow rate of $0.2 \mathrm{~L} \mathrm{~min}^{-1}$ was continuously injected into the cylinder to dilute the $400 \mathrm{ppbv}$ sample. The dynamical concentrations of the continuously diluted sample were calculated by an exponential equation reported in literature (Gamez et al., 2008; Lovelock, 1961). This exponential dilution method was used to obtain the VUV-PI mass spectra using photoionizers $\mathrm{A}$ and $\mathrm{B}$ as well as the LODs of the instrument. A $1000 \mu \mathrm{L}$ MicroPette ${ }^{\mathrm{TM}}$ pipettor (Eppendorf Co. Limited), a $100 \mu \mathrm{L}$ MicroPette $^{\mathrm{TM}}$ pipettor (Eppendorf Co. Limited), and an ordinary injection syringe were used in the preparation. The uncertainty for dilution was estimated to be $\pm 5 \%$.

For the measurement of urban air, outdoor air was introduced into the VUV-PIMS through a stainless tube $(240 \mathrm{~cm}$ length, $1 / 8$ inch OD). The tube was heated at $\sim 60^{\circ} \mathrm{C}$, and a glass microfiber filter (aperture size: $0.7 \mu \mathrm{m}$ ) was placed at the inlet of the tube to filter the particles present in the outdoor air. The end of the tube was set at $\sim 2 \mathrm{~m}$ from the outer wall of the laboratory building and at a height of $\sim 20 \mathrm{~m}$ from the ground.

Benzene (Beijing Beihua Fine Chemicals Co. Ltd., $>99.5 \%$ ) and dichloromethane (J. T. Baker Co., chromatographic grade) were used in the experiment. High-purity nitrogen (>99.999\%) and high-purity oxygen (>99.999\%) were purchased from Beijing Haikeyuanchang Practical Gas Co. Ltd. and Beijing Huayuan Gas Chemical Industry Co. Ltd, respectively.

\section{Results and discussion}

\subsection{Mass spectra obtained with photoionizers A and B}

Figure $2 \mathrm{a}$ and $\mathrm{b}$ show the mass spectra of 0 and $8.6 \mathrm{ppbv}$ benzene in synthetic air, respectively, which were obtained using photoionizer A. In each spectrum, strong mass peaks are observed at an $\mathrm{m} / \mathrm{z}$ of $28\left(\sim 2 \times 10^{5}\right.$ counts $)$ and 32 ( $\sim 3 \times 10^{5}$ counts), which correspond to the background ions of $\mathrm{N}_{2}^{+}$and $\mathrm{O}_{2}^{+}$, respectively. $\mathrm{N}_{2}$ (ionization potential $=15.6 \mathrm{eV}$ ) and $\mathrm{O}_{2}$ (ionization potential $=12.1 \mathrm{eV}$ ) are not ionized by the $10.0 \mathrm{eV}$ VUV photons emitted from the krypton lamp (Shu et al., 2013), but they are ionized by the bom- 
bardment of accelerated light-induced electrons (photoelectron ionization, PEI) (Gamez et al., 2008; Muhlberger et al., 2001) [Wiley, 1955]. For photoionizer A, VUV light directly illuminates the ion lenses biased at dozens of volts, thereby generating numerous photoelectrons with kinetic energies of dozens of electron volts (photoelectric effect). These energetic photoelectrons induce several secondary $\mathrm{N}_{2}^{+}$and $\mathrm{O}_{2}^{+}$ species. The noise levels of the mass spectra shown in Fig. 2a and $b$ are as high as $263.6 \pm 15.7$ counts, predominantly caused by stray VUV photons in the TOF chamber and secondary ions formed outside the focusing region of the ion lenses. Furthermore, in the inset of Fig. 2b, a mass peak is observed at an $m / z$ of 78 , corresponding to the molecular ion of benzene. The mass resolution at an $m / z$ of 78 is $\sim 200$. Meanwhile, small mass peaks are observed at $m / z$ values of $16,18,19$, and 44 , corresponding to $\mathrm{O}^{+}, \mathrm{H}_{2} \mathrm{O}^{+}, \mathrm{H}_{3} \mathrm{O}^{+}$, and $\mathrm{CO}_{2}^{+}$, respectively; these peaks are also generated by PEI. Moreover, other small mass peaks are observed at $\mathrm{m} / \mathrm{z}$ values of 29 and 34, possibly attributed to the impurities present in synthetic air.

Figure $2 \mathrm{c}$ and d show the mass spectra of 0 and $8.6 \mathrm{ppbv}$ benzene in synthetic air, respectively, recorded using photoionizer B. Compared with the mass spectra in Fig. 2a and b, those in Fig. 2c and d exhibit a decrease in the intensities of $\mathrm{N}_{2}^{+}$and $\mathrm{O}_{2}^{+}$mass peaks by 3 orders of magnitude. This decrease is attributed to the fact that the optical baffle of photoionizer B prevents VUV light from entering the ion-migration lens assembly; as a result, the formation of $\mathrm{N}_{2}^{+}$and $\mathrm{O}_{2}^{+}$is significantly suppressed. Meanwhile, the baseline level decreases from $263.6 \pm 15.7$ counts (Fig. 2a) to $4.1 \pm 1.8$ counts (Fig. $2 \mathrm{c}$ ). On the other hand, the mass signal intensity for benzene observed in Fig. $2 \mathrm{~d}$ is slightly higher than that observed in Fig. 2b. Such an enhancement in the photoionization efficiency possibly originates from the reflectance of VUV light by the optical baffle in photoionizer B (Zhu et al., 2014). In addition, Fig. 2d shows relatively strong mass peaks at $m / z$ values of 19,37 , and 55 , which correspond to $\mathrm{H}_{3} \mathrm{O}^{+}$(protonated water), $\left(\mathrm{H}_{2} \mathrm{O}\right)_{2} \mathrm{H}^{+}$, and $\left(\mathrm{H}_{2} \mathrm{O}\right)_{3} \mathrm{H}^{+}$(protonated water clusters), respectively. Protonated water and water clusters are formed by multiple molecular reactions (Hansel et al., 1995).

The above experimental results indicate that photoionizer $B$ significantly reduces the background noise. Hence, the VUV-PIMS with photoionizer B is further calibrated and used for outdoor measurements.

\subsection{Limits of detection}

To demonstrate its linearity of response as well as detection sensitivity, VUV-PIMS was calibrated using benzene. The benzene concentrations employed in the calibration were in the low ppbv range considering that benzene is present at the level of several micrograms per meter in the atmosphere (Cheng et al., 2010). Figure 3 shows the linear calibration curve and the corresponding linear regression

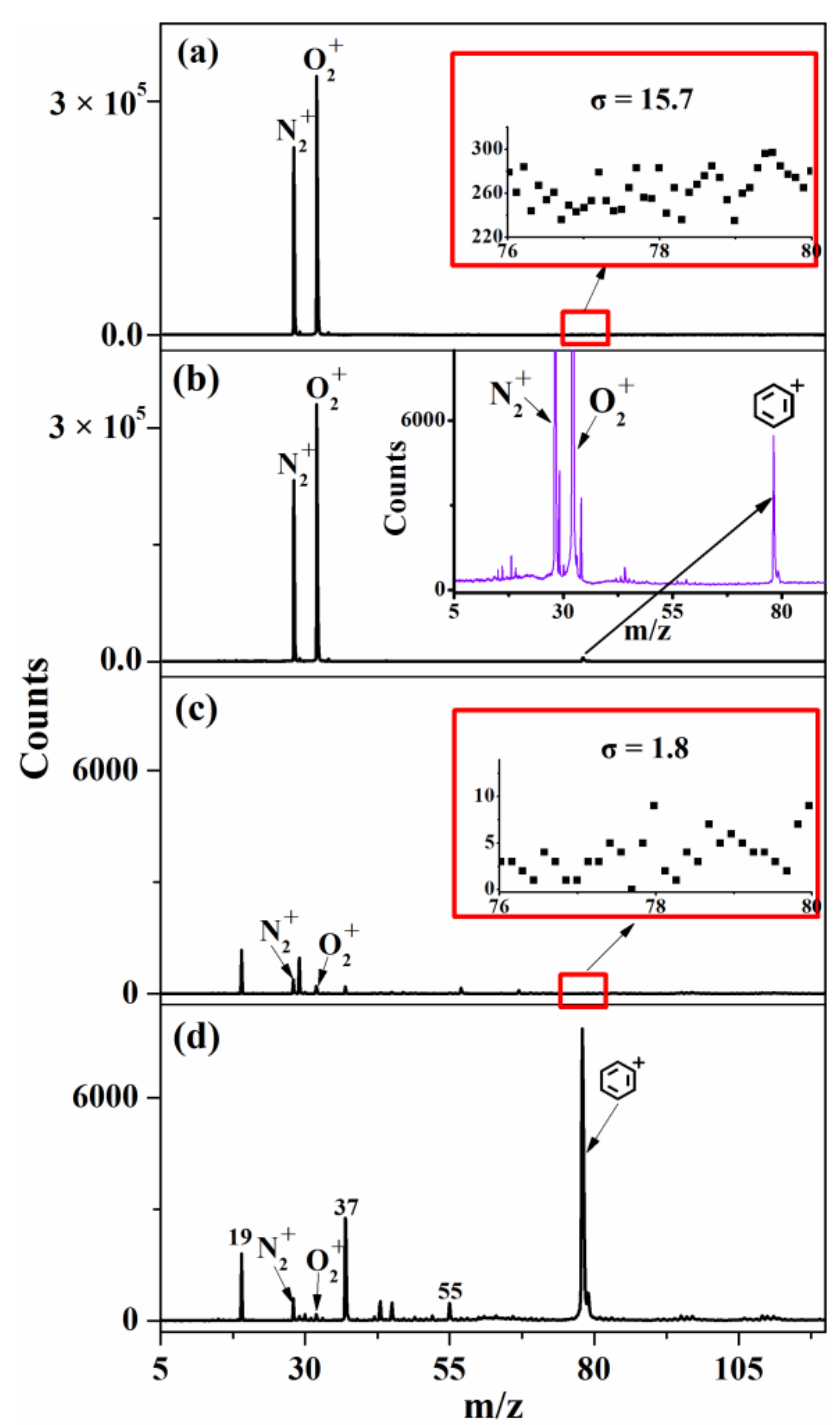

Figure 2. Mass spectra of synthetic air (a) and $8.6 \mathrm{ppbv}$ benzene (b) obtained with photoionizer A. Mass spectra of synthetic air (c) and 8.6 ppbv benzene (d) obtained with photoionizer B. The acquisition time for each mass spectrum is $10 \mathrm{~s}$. The insets in Fig. 2a and c show the magnified baselines of the mass spectra at an $m / z$ of 78 . The inset in Fig. 2b shows the magnification of the benzene mass peak.

equation $(y=1.5+1254 \times)$. A satisfactory linear response $\left(R^{2}=0.997\right)$ is obtained over 3 orders of magnitude. The slope of the fitted line indicates that the detection sensitivity of the VUV-PIMS is $\sim 1.25 \pm 0.02$ counts pptv $^{-1}$ (an uncertainty of 0.02 is obtained from five measurements).

The LOD for benzene at a signal-to-noise ratio of 2 is estimated by LOD $=2 \sigma c / h$ (Muhlberger et al., 2001), where $\mathrm{c}$ is the sample concentration, $\sigma$ is the standard deviation of the noise, and $\mathrm{h}$ is the ion signal intensity. Detection sensitivity is given by $h / c$. Based on the mass spectra shown in 


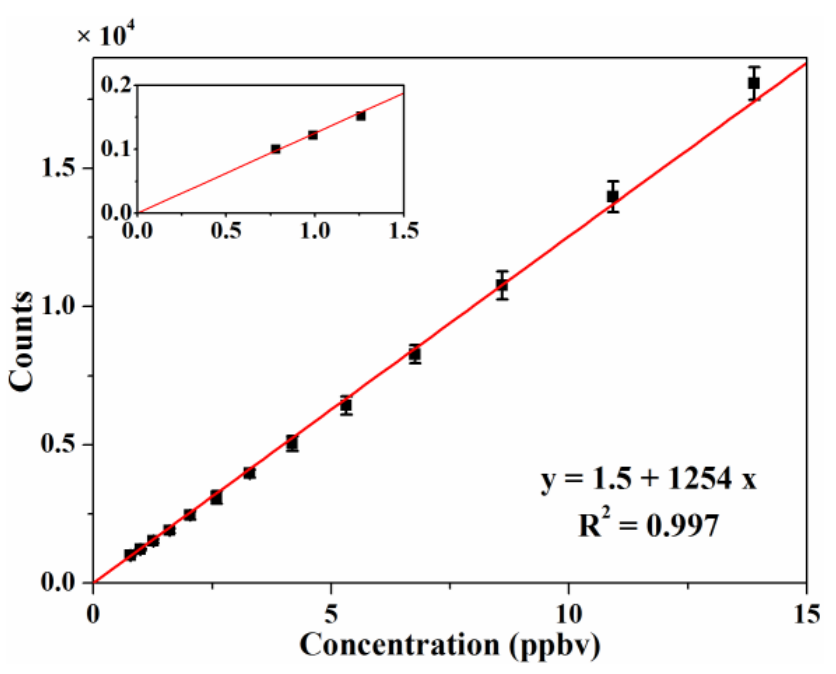

Figure 3. Signal intensities versus concentrations of benzene measured by the VUV-PIMS equipped with photoionizer B. Black squares represent the data points, and the line represents the result from linear fitting.

Fig. $2 \mathrm{c}, \sigma$ is determined to be 1.8. The LOD is calculated to be $\sim 3$ pptv.

Table 1 shows the sensitivities of similar instruments reported in literature. Compared with the series of lamp-based VUV-PIMS developed by Mühlberger et al. (2007, 2005a, b, 2002) and that by Hua et al. (2011), the VUV-PIMS developed herein exhibits an improvement in sensitivity by 3 orders of magnitude. The sensitivity of this instrument even exceeded that of the lamp-based VUV-PI-ion-trap-MS developed by Kuribayashi et al. (2005). Considering that both Kuribayashi et al. and our group utilized similar VUV photon fluxes, we believe that the ion-migration lens assembly designed herein is very effective. The sensitivity of this instrument is close to that of the mobile resonance-enhanced multiphoton ionization MS designed by Heger et al. (1999) and the widely used PTR-MS (de Gouw and Warneke, 2007).

\subsection{Atmospheric measurements}

To demonstrate the utility of the developed VUV-PIMS for field measurements further, real-time measurements of urban air were conducted for 6 days between 7 March 2015 and 12 March 2015. Air from outside our laboratory building (Beijing, China) was continuously sampled into the VUV-PIMS. The operating parameters were the same as those employed in the benzene calibration study. Spectra were recorded every 3 min.

Figure 4 shows the VUV-PIMS spectrum recorded at 00:14 (China Standard Time) on 7 March 2015, when the intensity of the benzene peak was the maximum during measurement. In the spectrum, a series of strong mass peaks are observed at $m / z 19,37,55,73$, and 91, corresponding to $\mathrm{H}_{3} \mathrm{O}^{+},\left(\mathrm{H}_{2} \mathrm{O}\right)_{2} \mathrm{H}^{+},\left(\mathrm{H}_{2} \mathrm{O}\right)_{3}^{+},\left(\mathrm{H}_{2} \mathrm{O}\right)_{4} \mathrm{H}^{+}$, and $\left(\mathrm{H}_{2} \mathrm{O}\right)_{5} \mathrm{H}^{+}$,

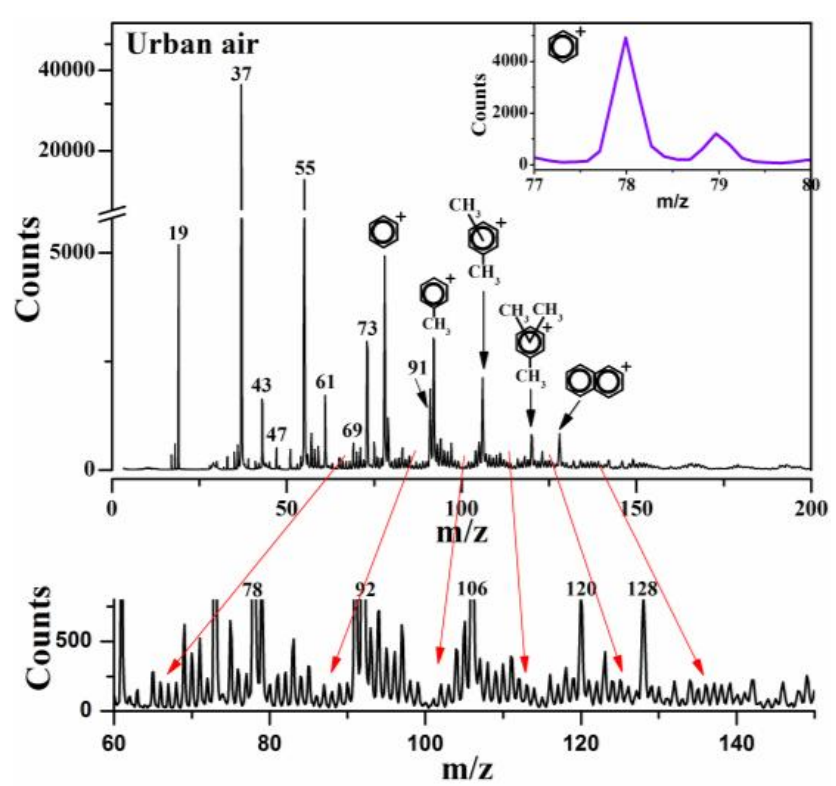

Figure 4. Mass spectrum of outdoor air obtained using the VUVPIMS at 00:14 on 7 March 2015. The magnified plots are discussed in the text.

respectively. Mass peaks are also observed at $m / z$ 43, 47, $61,69,78,92,106,120,128$, and others with comparatively lower intensities (See the magnified plot in Fig. 4), corresponding to VOCs. Based on the measurement results of atmospheric VOCs by GC-MS in the same area from 2000 to 2005 (Jiang, 2006), the mass peaks at $\mathrm{m} / z$ values of $78,92,106,120$, and 128 can be attributed to benzene, toluene, xylene/ethylbenzene, $\mathrm{C}_{3}$-alkylated benzene derivatives, and naphthalene, respectively. In urban environments, benzene, its alkylated derivatives, and naphthalene mainly originate from automotive exhaust. They are potential carcinogens and are involved in photochemical reactions (Lee et al., 2005). The mass peaks at $m / z 43,47,61$, and 69 are speculated to be protonated VOCs because of the presence of a large amount of $\mathrm{H}_{3} \mathrm{O}^{+}$observed in the mass spectrum. Atmospheric formic acid, acetic acid, and isoprene may form these ions via PTR (de Gouw and Warneke, 2007). Other mass peaks are not assigned in this study.

A magnified image of the mass spectrum around mass peaks at $m / z 78$ and 79 is shown in Fig. 4. From the magnified image, the signal intensities at $m / z 78$ and 79 represent 4957 counts and 1212 counts, respectively; i.e., their intensity ratio $\left(\mathrm{I}_{78} / \mathrm{I}_{79}\right)$ is $1: 0.24$. However, according to the carbon isotope ratio of ${ }^{12} \mathrm{C} /{ }^{13} \mathrm{C}$, the theoretical $\mathrm{I}_{78} / \mathrm{I}_{79}$ should only be $1: 0.067$. Thus, the PTR may contribute to the formation of the mass peak at $m / z 79$. By deducting the isotopic contribution $\left({ }^{13} \mathrm{C}^{12} \mathrm{C}_{5} \mathrm{H}_{6}^{+}\right), \sim 874$ counts can be assigned to ${ }^{12} \mathrm{C}_{6} \mathrm{H}_{7}^{+}$. Hence, the 874 count signal is estimated to be contributed by PTR. 
The presence of protonated water and water clusters complicates the mass spectrum. A metal mesh piece was attached to the side of the photoionizer connecting to the VUV lamp to abate ion formation. However, this phenomenon cannot be absolutely eliminated under the current design of the instrument.

Figure 5a-d show the variations in the concentrations of benzene, toluene, xylene/ethylbenzene, and $\mathrm{C}_{3}$-alkylated benzene derivatives by continuous monitoring by the VUVPIMS, respectively, and Fig. 5e shows the real-time wind speeds as measured by a meteorological station at a distance of $\sim 200 \mathrm{~m}$ from the laboratory for 6 days. The concentration variation of benzene and its derivatives exhibit similar characteristics. In addition, they exhibit a remarkable opposite trend to the wind speeds. The concentrations of benzene $(\mathrm{m} / \mathrm{z}, 78)$ are quantified by the abovementioned calibration and are found to range between 0.1 and $3.2 \mathrm{ppbv}$, which is consistent with the reported average level of the benzene concentration in the same area from 2000 to 2005 (4.0 ppbv) (Jiang, 2006). The concentrations of benzene from 10:00 CST on 8 March $2015(3 / 8,10: 00)$ to $17: 00$ on 10 March $2015(3 / 10,17: 00)$ are in the range of $0.1-0.3 \mathrm{ppbv}$. A calibration with the $10 \mathrm{ppbv}$ sample of benzene was conducted at 13:00 on 8 March 2015 (3/8 13:00) to check the instrument. The results indicated that the instrument operates normally during this time.

\section{Conclusions}

A lamp-based VUV-PIMS was developed in our laboratory. The photoionizer with an optical baffle significantly reduced the background noise. An LOD of 3 pptv was achieved for benzene. The PIMS developed herein exhibited sensitivity for VOCs better than that exhibited by VUV photoionization MSs reported previously (Kuribayashi et al., 2005; Muhlberger et al., 2007; Muhlberger et al., 2005a; Muhlberger et al., 2005b). A satisfactory linear response $\left(R^{2}=0.997\right)$ was obtained. The initial atmospheric measurement demonstrates that the instrument can be used for the real-time monitoring of trace-level VOCs in the atmosphere.

Acknowledgements. This study is supported by the Strategic Priority Research Program of the Chinese Academy of Sciences (XDB05040501), National Natural Science Foundation of China (grant no. 21277155), and Creative Research Groups of China (grant no. 51221892). The authors would like to acknowledge the staff of the Beijing Urban Ecosystem Research Station for providing data for wind speeds and Junfeng Liu of RCEES for his help during instrument calibration.

Edited by: M. Hamilton
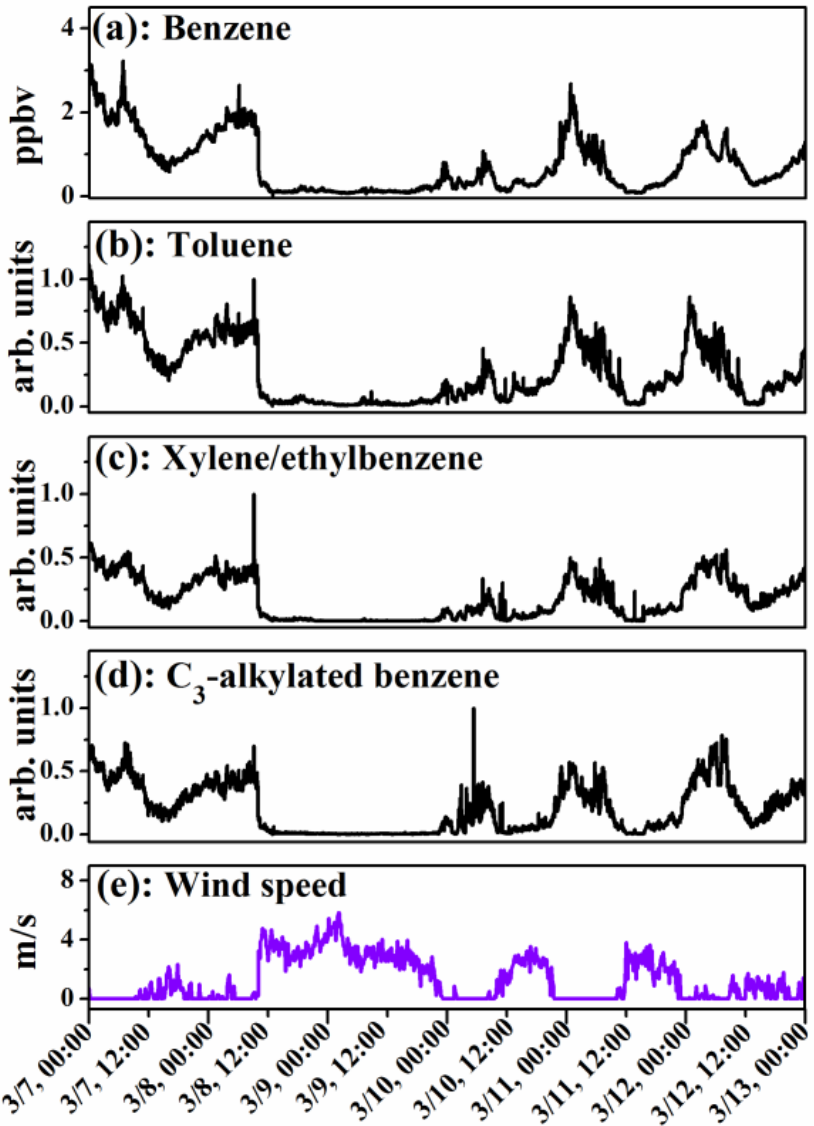

Date and Time

Figure 5. Outdoor measurements for 6 days: concentration variation of benzene (a), toluene (b), xylene/ethylbenzene (c), and $\mathrm{C}_{3}$ alkylated benzene derivatives (d) monitored by the VUV-PIMS Data for wind speeds (e) were obtained from the Beijing Urban Ecosystem Research Station.

\section{References}

Cheng, M. H. Y., Coalson, R. D., and Tang, P.: Molecular dynamics and brownian dynamics investigation of ion permeation and anesthetic halothane effects on a proton-gated ion channel, J. Am. Chem. Soc., 132, 16442-16449, 2010.

de Gouw, J. and Warneke C.: Measurements of volatile organic compounds in the earths atmosphere using proton-transferreaction mass spectrometry, Mass Spectrom. Rev., 26, 223-257, 2007.

Elsom, D. M.: Smog alert: Managing urban air quality, Earthscan Publications, 1996.

Gamez, G., Zhu, L., Schmitz, T. A., and Zenobi, R.: Photoelectron emission as an alternative electron impact ionization source for ion trap mass spectrometry, Anal. Chem., 80, 6791-6795, 2008.

Gee, I. L. and Sollars, C. J.: Ambient air levels of volatile organic compounds in Latin American and Asian cities, Chemosphere, 36, 2497-2506, 1998.

Hansel, A., Jordan, A., Holzinger, R., Prazeller, P., Vogel, W., and Lindinger, W.: Proton-transfer reaction mass-spectrometry - on- 
line trace gas-analysis at the ppb level, Int. J. Mass Spectrom., 149, 609-619, 1995.

Heger, H. J., Zimmermann, R., Dorfner, R., Beckmann, M., Griebel, H., Kettrup, A., and Boesl, U.: On-line emission analysis of polycyclic aromatic hydrocarbons down to pptv concentration levels in the flue gas of an incineration pilot plant with a mobile resonance enhanced multiphoton ionization time-of-flight mass spectrometer, Anal. Chem., 71, 46-57, 1999.

Hua, L., Wu, Q. H., Hou, K.Y., Cui, H. P., Chen, P., Wang, W. G., Li, J. H., and Li, H. Y.: Single photon ionization and chemical ionization combined ion source based on a vacuum ultraviolet lamp for orthogonal acceleration time-of-flight mass spectrometry, Anal. Chem., 83, 5309-5316, 2011.

Jaouen, P., Gonzalezflesca, N., and Carlier, P.: Dynamic polluted atmosphere generator at low ppbv levels for validating VOC sampling methods, Environ. Sci. Technol., 29, 2718-2724, 1995.

Jiang, J.: Study on variation of trace volatile organic compounds in the atmosphere of Beijing. Doctor dissertation of Institute of Atmospheric Physics, Chinese Academy of Sciences, Beijing, China, 2006.

Kuribayashi, S., Yamakoshi, H., Danno, M., Sakai, S., Tsuruga, S., Futami, H., and Morii, S.: VUV single-photon ionization ion trap time-of-flight mass spectrometer for on-line, real-time monitoring of chlorinated organic compounds in waste incineration flue gas, Anal. Chem., 77, 1007-1012, 2005.

Lee, C., Choi, Y. J., Jung, J. S., Lee, J. S., Kim, K. H., and Kim, Y. J.: Measurement of atmospheric monoaromatic hydrocarbons using differential optical absorption spectroscopy: Comparison with on-line gas chromatography measurements in urban air, Atmos. Environ., 39, 2225-2234, 2005.

Lovelock, J. E.: Ionization methods for analysis of gases and vapors, Anal. Chem., 33, 162-178, 1961.

Muhlberger, F., Zimmermann, R., and Kettrup, A.: A mobile mass spectrometer for comprehensive on-line analysis of trace and bulk components of complex gas mixtures: Parallel application of the laser-based ionization methods VUV single-photon ionization, resonant multiphoton ionization, and laser-induced electron impact ionization, Anal. Chem., 73, 3590-3604, 2001.

Muhlberger, F., Wieser, J., Ulrich, A., and Zimmermann, R.: Single photon ionization (SPI) via incoherent VUV-excimer light: Robust and compact time-of-flight mass spectrometer for on-line, real-time process gas analysis, Anal. Chem., 74, 3790-3801, 2002.
Muhlberger, F., Hafner, K., Kaesdorf, S., Ferge, T., and Zimmermann, R.: Comprehensive on-line characterization of complex gas mixtures by quasi-simultaneous resonance-enhanced multiphoton ionization, vacuum-UV single-photon ionization, and electron impact ionization in a time-of-flight mass spectrometer: Setup and instrument characterization, Anal. Chem., 76, 67536764, 2004.

Muhlberger, F., Streibel, T., Wieser, J., Ulrich, A., and Zimmermann, R.: Single photon ionization time-of-flight mass spectrometry with a pulsed electron beam pumped excimer VUV lamp for on-line gas analysis: Setup and first results on cigarette smoke and human breath, Anal. Chem. 77, 7408-7414, 2005 a.

Muhlberger, F., Wieser, J., Morozov, A., Ulrich, A., and Zimmermann, R.: Single-photon ionization quadrupole mass spectrometry with an electron beam plumped excimer light source, Anal Chem. 77, 2218-2226, 2005b.

Muhlberger, F., Saraji-Bozorgzad, M., Gonin, M., Fuhrer, K., and Zimmermann, R.: Compact ultrafast orthogonal acceleration time-of-flight mass spectrometer for on-line gas analysis by electron impact ionization and soft single photon ionization using an electron beam pumped rare gas excimer lamp as VUV-light source, Anal. Chem., 79, 8118-8124, 2007.

Schubert, P., Rosenberg, E., and Grasserbauer, M.: Measurement of volatile organic compound (VOC) concentration profiles in the atmosphere of a remote forest region, Int. J. Environ. An. Ch. 75, 127-147, 1999.

Shu, X., Yang, B., Meng, J. W., Wang, Y. F., and Shu, J. N.: Vacuum ultraviolet photoionization mass spectra of typical organics contained in ambient aerosols, Spectrosc. Lett., 46, 227-234, 2013.

Tonokura, K., Kanno, N., Yamamoto, Y., and Yamada, H.: Development of a compact laser-based single photon ionization timeof-flight mass spectrometer, Int. J. Mass Spectrom., 290, 9-13, 2010.

Zhu, Z. X., Wang, J., Qiu, K. Q., Liu, C. Y., Qi, F., and Pan, Y.: Note: A novel vacuum ultraviolet light source assembly with aluminum-coated electrodes for enhancing the ionization efficiency of photoionization mass spectrometry, Rev. Sci. Instrum., 85, 046110, doi:10.1063/1.4871796, 2014. 